\title{
LA FIGURA DE LA MUJER EN EL CINE DE ALMODÓVAR
}

\author{
THE FIGURE OF WOMAN IN ALMODOVAR'S CINEMA
}

María Mar Soliño Pazó

Universidad de Salamanca

\section{Resumen:}

Almodóvar es uno de los directores españoles más famosos. Si por algo es conocido es por darle un papel relevante a la mujer. En sus películas encontramos mujeres que poseen un fuerte carácter, pero que al mismo tiempo sufren mucho debido a su soledad. En este artículo se analizarán los factores que tienen en común todas esas mujeres.

\section{Palabras clave:}

mujer, película, director

\section{Abstract:}

Almodóvar is one of the most famous Spanish movie director. He is well-known for giving an important role to women. In his films we can find women with a strong personality but at the same time, they suffer a lot from isolation. In this article we will analyse the aspects tha the women have in common.

\section{KeY WORDS:}

woman, film, movie director 


\section{INTRODUCCIÓN}

Es bien sabido que hay muy pocos directores de cine en España que entienda cómo se siente una mujer en cualquier circunstancia, de tal forma que muchas de nosotras nos sentimos identificadas cuando vemos alguna película de Almodóvar. Todo ello, ha traspasado las fronteras de nuestro país y, ya no sólo las actrices españolas están deseando trabajar con él, sino que también desean tener esa oportunidad las actrices no hispanas. Esto, unido a que las actrices que trabajan con Almodóvar adquieren un enorme prestigio cuando trabajan con él, hace que el director sea uno de los más queridos entre la gran mayoría de las actrices. De hecho, surgió hace muchos años el apelativo de "chica Almodóvar" o "las chicas de Almodóvar" y muchas de estas actrices están deseando quedar incluidas bajo este mote, incluso Joaquín Sabina escribió e interpretó una canción titulada "Yo Quiero ser una Chica Almodóvar", en la que describe a la perfección lo que significa quedar incluida bajo esta denominación. Entre esas musas destacan: Carmen Maura, Marisa Paredes, Bibiana Fernández (antes conocida como Bibí Ándersen), Victoria Abril, María Barranco, Chus Lampreave, Rossy de Palma, Antonia San Juan, Rosa María Sardá, Verónica Forqué y Penélope Cruz.

\section{PEDRO ALMODÓVAR Y EL UNIVERSO FEMENINO}

La base de las películas de Pedro Almodóvar es la mujer. Este gran director y guionista manchego consigue que a cualquier mujer se la vea como algo hermoso, primordial y único, en que ella sola puede llenar toda la pantalla del cine.

Las mujeres de Almodóvar Son fuertes, luchadoras, autoSuficientes, pero Sufren mucho y tienen como denominador común que están Solas, aunque son plenamente dueñas de su propia soledad. La mujer es el Sujeto del cine de Pedro Almodóvar y llena toda la película, tanto en el Sentido visual como en el interpretativo, convirtiéndoSe en la protagonista abSoluta, Sin depender de ninguna manera del perSonaje masculino. Son mujeres coraje que luchan contra las adverSidades de la vida y la psicología de la mujer es el eje principal del relato de la producción cinematográfica de Almodóvar. Las mujeres de Almodóvar Sienten la opresión de sus circunStancias y este sentimiento de opresión, Se traducen en un deseo de cambio, huída y mejora de sus Situaciones.

En las películas de Almodóvar Se desarrollan normalmente loS celoS, la traición y el Sentimiento de culpa. Según declaró el propio Almodóvar a un periódico holandéS (Allgemeen Dagblad, 2009) "las mujeres resisten mejor que loS hombres loS golpes de la vida; esta capacidad de resistencia siempre me ha inSpirado". Y, es precisamente, ese sentimiento el que ha estado presente en todas Sus producciones, desde Mujeres al borde de un ataque de nervios (1988), pasando por Todo sobre mi madre (1999) o Abrazos rotos (2009). 
Para el director manchego el centro de sus películas ha sido siempre la mujer; tan sólo Se saltó esa "regla de oro" en dos películas: La Mala educación (2004) y Hable con ella (2002). En la primera ni siquiera aparecen mujeres a lo largo de todo el film, tan sólo la actriz Leonor Walting hace una pequeña aparición como maquilladora. En la segunda producción las mujeres sí aparecen, pero tienen un papel completamente secundario y la historia se centra en torno a los hombres y la amistad de dos hombres.

El amor por las mujeres a Almodóvar le ha llevado a emplear en su producción filmográfica mucho los estereotipos femeninos, siendo algunos de éstos:

La mujer enamorada: En La Flor de mi secreto (1995) el personaje protagonista Leo Macías (encarnado por Marisa Paredes) es una mujer que vive por y para su marido. Él es militar (Imanol Arias), "experto en conflictos internacionales", en la boca de la propia Leo (como el conflicto de Bosnia) y está mucho tiempo fuera de casa. Ella es una escritora de novela rosa que escribe bajo el pseudónimo de Amanda Gris. Es una mujer depresiva por falta de hombre, débil porque necesita siempre tener una presencia masculina cerca de ella y no entiende por qué no puede tener al hombre que quiere a su lado y una vida en familia, que es todo lo que una mujer - según Leodesea en la vida para ser feliz. Además, necesita el apoyo constante de los demás, es una mujer dependiente de los demás, la vida se le complica con pequeñeces (a tal grado que es su mejor amiga que le quita las botas que le oprimen - aunque lo que realmente le oprime es la relación con su marido - pues ella sostiene que no puede). Su mejor amiga - Betty -, amante de su esposo y psicóloga está representada por Carmen Elías. Las novelas que escribe Leo comienzan a fracasar en el momento en que fracasa también completamente su matrimonio y pierde ya a su marido Paco (Imanol Arias). Fracasa para su editora, porque comienza a escribir otro género "novela negra". La falta del hombre no le permite ser feliz en ningún aspecto hasta que conoce otro tipo de hombre, Ángel (Juan Echanove).

La ama de casa, desesperada, histérica, harta de hacer cada día lo mismo y un tanto esperpéntica, es la que representa Carmen Maura en ¿Qué he hecho yo para merecer esto? (1984) Gloria, una ama de casa, una mujer de su casa, comparte el poco espacio de su casa con su suegra, su marido y sus hijos. Casada con un machista, celoso, gruñón, con un hijo traficante de drogas y adicta a los tranquilizantes, cuya única amiga es una vecina prostituta. Esta película es un canto de liberación de la ama de casa.

Las prostitutas: en muchas películas han salido prostitutas y una de ellas ha sido el personaje que encarna magníficamente Verónica Forqué en ¿Qué he hecho yo para merecer esto? (Cristal). Pedro Almodóvar presenta a la prostituta como aquella mujer que ejerce su profesión de forma natural y no reniega de ello. En esta película se presenta a Cristal dentro de un ámbito doméstico, a pesar de su trabajo, está en casa. Otra de las prostitutas del cine almodovariano es Agrado o La Agrado interpretado 
por Antonia San Juan en Todo sobre mi madre (1999), a este personaje se le puede enmarcar en dos categorías, ya que además de ser prostituta es transexual. En este caso presenta la profesión de una manera más dura, pero apoyado en el humor suaviza las situaciones de tensión. Almodóvar presenta los típicos estereotipos para presentar estos personajes en sus filmes: el descaro, la ropa de colores chillones, desconjuntada, hortera y de tallas más pequeñas de lo normal. Cuando aparecen en su "lugar de trabajo", están relacionadas siempre con el estereotipo de la droga y el maltrato físico. No queremos dejar de mencionar el comienzo de la película Carne Trémula(1997) donde una prostituta (Isabel Plaza - interpretado por Penélope Cruz) da a luz en un autobús (nace Víctor Plaza uno de los protagonistas, encarnado por Liberto Rabal). Aquí se conjugan dos estereotipos almodovarianos, la prostitución y la maternidad. También aparece la prostituta ninfómana reflejada en Sexilia (Cecilia Roth en Laberinto de Pasiones, 1982).

Los transexuales: muchoS de loS perSonajes de la filmografía del director manchego tienen esta caracteríStica. TodoS Son hombres que se han cambiado de sexo para ser mujeres o que se visten de mujer en algunas ocasiones. En Tacones Lejanos (1991), Miguel BoSéSe viste de mujer para interpretar a su cantante preferida en un club, Femme Letal. Sin embargo, en Su vida normal, realiza el trabajo de juez (el Juez Domínguez) y mantiene completamente en Secreto Su afición por el travestismo. Otro perSonaje que se traviste es Gael García Bernal (Juan o Ángel) en La Mala Educación(2004). Emplea los estereotipos del afán por el sexo, las drogas y las enfermedades contagiadas sexualmente. Volveremos a este apunte más adelante.

Las madres (o la maternidad): este papel es uno de los más importantes para Pedro Almodóvar. Él ha estado muy unido a su madre y este vínculo aparece en casi todas sus películas. El denominador común de las madres de Almodóvar es una madre volcada en sus hijos, un estereotipo bastante claro sobre la mujer: la madre cuida de sus hijos a toda costa. Se puede ver en toda la filmografía, así en ¿Qué he hecho yo para merecer esto? (1984) tenemos dos tipos de madres: la suegra, que cuida de su hijo pero a la nuera le hace la vida nada fácil (interpretada por Chus Lampreave, que también hace de madre anciana y sabía que aconseja a su hija en La flor de mi secreto). Las madres más atípicas del cine de Almodóvar son Bécky del Páramo representado por Marisa Paredes en Tacones Lejanos (1991), y que interpreta a una famosa cantante que deja de lado a su hija, no como Se supone que tiene que hacer una madre. Aquí podemos observar otro estereotipo, la mujer que para triunfar tiene que dejar de lado su lado familiar. La otra madre atípica es Gloria (Carmen Maura) en ¿Qué he hecho yo para merecer esto? Que regala a su hijo a un dentista, porque no tiene dinero suficiente paramantener la familia. También podemos encontrarnos con madres destrozadas por 
la pérdida de un hijo, como Manuela (Cecilia Roth) en Todo sobre mi madre (1999). La maternidad viste, por tanto, de forma muy diferente en las películas de Almodóvar.

Los personajes femeninos del cine de Almodóvar van evolucionando con el tiempo, de tal forma que la mujer sumisa se rebela, la madre transexual, la madre que enloquece porque su marido no la quiere, la mujer independiente que deja de lado la maternidad para triunfar profesionalmente o la mujer independiente que mantiene a su hijo ella sola, o la mujer que pierde la conciencia cuando muere su marido y tiene que superar como sea el dolor que esto le produce. Todas ellas son mujeres que se rebelan, que luchan, que intentan salir adelante. La mujer refleja en el cine de Almodóvar el corazón del mundo, las emociones y los sentimientos, el origen de la vida y del amor o como se dice en Todo sobre mi madre "Ser madre es una putada". Estos estereotipos que hemos presentado son los que traspasa Almodóvar al espectador a través de sus películas.

No obstante, estas mujeres almodovarianas necesitan que la sociedad acepte como normales todas sus conductas e identidades sexuales. Ser normal en términos sexuales, lingüísticos, raciales, físicos, etc. equivale a no verse disminuido por ser gay, por no hablar una determinada lengua, por no ser de una raza determinada o por tener una discapacidad física. Estas cuestiones de género nos llevan a hacer del cine de Pedro Almodóvar una lectura deconstructiva.

El cine deconstructivo funciona mediante un proceso de ruptura, que se genera al crear una cierta inquietud al espectador a partir de establecer una relación entre el texto fílmico y el público espectador, siendo este último imprescindible para descifrar el significado del conjunto fílmico, esto es de la película. Esto representa lo extraño, lo raro, lo excéntrico, lo queer que están presentes en la filmografía de Almodóvar y Se evocan a través de imágenes de gays, lesbianas, drags, transexuales, travestis, etc. Esto quiere decir que los referentes fílmicos de Almodóvar giran en torno al concepto del cine queer.

\section{ALMODÓVAR Y EL MUNDO QUEER}

Los binarismos producidos por la sociedad están pues presentes en toda la filmografía de Almodóvar. Esto quiere decir que lo heterosexual/el lesbianismo/lo homosexual, la oposición mujer/hombre, lo femenino versus a lo masculino se reflejan en todo el cine de Almodóvar y éstas son precisamente base de las teorías queer. Así, por ejemplo, en la película Matador (1986) y La mala educación (2004), se ve claramente que lo queer es objeto de burla en el texto, donde los personajes masculinos de Almodóvar cuestionan todo aquello que no se amolda a uno de los extremos del binomio hombre-mujer, ya sea a través de especulaciones sobre los otros hombres o sobre ellos mismos. Así 
pues, parece que en la filmografía de Almodóvar la identidad en sí misma es una pura construcción y los personajes de Almodóvar, tienen una doble ficción.

Si partimos de que el género es la construcción social de la diferencia biológica sexual, Judith Butler sostiene que además (y cito) "es una identidad instituida mediante la repetición de actos estilizados", donde el libreto y el escenario anteceden al sujeto; Eve K. Sedgwich, en diálogo con la teórica anterior, añade que el género debe de ser entendido como la interpretación o significación cultural del hecho biológico.

Almodóvar es quien pone en escena el desplazamiento producido entre lo que la norma quiere decir y quien la ejecuta, por ello representa la dimensión preformativa de la que hablan estas dos autoridades de la Queer Theory. Para entender mejor esto pensemos en todo sobre mi madre (1999), film dedicado por entero al travestismo, al drag, a este carácter actuado y a la traspolación de los inamovibles roles de género (siempre cuestionables ¿?). El personaje Agrado (protagonizado por Antonia San Juan), después de dar cuenta al público del teatro de todo lo que ha invertido en su femenina apariencia, explica que: “Una es más auténtica, cuanto más se parece a lo que ha soñado de sí misma". No habla de 'autenticidad' como original sino como ideal y constructo, que sólo es posible al desmontar y re- significar los referentes existentes.

Lo queer se define también por su carácter transformacional; recordemos otra escena de Todo sobre mi madre (1999), la frase que Manuela (Cecilia Roth), refiriéndose a Lola (antes Esteban, protagonizado por Toni Cantó) le dice a la Hermana Rosa (Penélope Cruz) en la sala de espera del hospital: “¿Cómo se puede ser tan machista con semejante par de tetas?". Este film representa además un profundo cuestionamiento a aquello que por estar instituido no se debería poner en tela de juicio, como por ejemplo: el rol de la madre. Aquí la maternidad se disocia de la escena institucional de la familia y da cabida a interpretaciones queer de la subjetividad, ¿o es Lola el padre (¿madre?) de los dos Esteban? ¿Es Rosa o Manuela la madre del pequeño Esteban (Eloy Azorín), que en poco tiempo "negativiza" la enfermedad del SIDA que Lola ha transmitido a Rosa y ella a su vez a su hijo? ¿Por qué Manuela le aclara con tanto énfasis a Rosa que ella no es su madre?

La figura de la masculinidad se profana y se disuelve, no sólo a través del travestismo de Lola, sino del Alzheimer del padre de Rosa, y de la muerte de los dos Esteban, ¿o cuando uno de los actores ("heterosexual") de un tranvía llamado deseo le pide a Agrado en el camerino que le haga una felación, aquí también se difumina en el constante juego de palabras que confunde a los personajes y cuestiona al espectador sobre su concepción de la paternidad y la maternidad, y, en general, de los roles de género. 
Almodóvar realiza como hemos dicho con anterioridad un cine deconstructivo al tratar temas marginales con actrices que suelen garantizar el éxito en taquilla (Marisa Paredes, Cecilia Roth, Penélope Cruz, Carmen Maura entre otras) y los temas que trata este director manchego no los trata el cine clásico, bien los ignora o bien los oculta, por ello podemos hablar de que el cine de Almodóvar representa lo que se denomina el anticine.

El anticine marcado de Almodóvar representa también el carácter circunstancial de la performatividad/actuación en la construcción subjetiva del género, ejemplificaremos esta idea con Tacones lejanos (1991): cuando el yerno de Bécky del Páramo le pregunta con insistencia a Femme Letal por el género de su nombre: - “¿Perdona, pero Letal es masculino o femenino?", Femme Letal responde: - “Depende, para ti soy un hombre".

O en Matador (1986), en el baño de hombres María Cardenal (interpretado por Asumpta Serna) le pregunta a Diego Montes (interpretado por Nacho Martínez): ““ ¿Por qué me sigues?", y él responde: - "Es el lavabo de hombres, ¿no has visto el letrero?", y ella agrega: -"No te fíes de las apariencias", pasando a ser entonces 'las apariencias' un constructo que no remiten necesariamente al original, en el caso de que lo hubiera..

Pensamos que la deconstrucción de la identidad de género se apoya en el cine almodovariano en el desarme de la identidad individual y que el director lo logra a través de la ridiculización de los nombres propios asignados a las personas para ser identificadas y diferenciadas unas de otras. Aunque insistimos que se pone entre dicho en el caso de los nombres de Esteban y de Rosa, en Todo sobre mi madre.

Hemos observado lo que ocurre con los nombres propios en otras películas: un lagarto se llama Dinero por ser verde (en ¿Qué he hecho yo para merecer esto?, 1984), una de las monjas del Convento de las Redentoras Humilladas se llama Sor Rata del Callejón (en Entre Tinieblas, 1983), Agrado (en Todo sobre mi madre, 1999) porque toda su vida la ha dedicado a hacerle la vida agradable a los demás, la actriz se autonombra Huma Rojo porque fuma mucho y tiene el pelo rojo (en Todo sobre mi madre, 1999), la prostituta Sexilia (en Laberinto de Pasiones, 1982), Letal (en Tacones Lejanos, 1991), etc. Almodóvar para deconstruir las instituciones subraya la monosexualidad de éstas y las habita de personajes queer, poniendo también en escena diversos grupos con la misma característica, por ejemplo el convento de monjas ya mencionado de Entre Tinieblas (1983), el internado de curas de La mala educación (2004), el grupo de "amigas" de Manuela (Todo sobre mi madre, 1999), los cuerpos de policía ridiculizados en Carne Trémula (1997), etc.

\section{CONCLUSIONES}


Podríamos pasar(noS) horas analizando los personajes, circunstancias, cuestionamientos, frases, conceptos, imágenes, etc. que Almodóvar pone en escena, construye y deconstruye sobre los géneros, pero en esta breve aportación, y sólo a manera de reflexión, cabría añadir que en general esta operación-producción cultural es articulada por una minoría queer, en el sentido amplio del término; sin embargo, el significado de lo queer es necesariamente pospuesto, porque no es nada todavía: la esperanza no radica en lo hecho, donde las posibilidades están ya agotadas, sino en lo que aún falta por hacer, pensar y construir: el devenir. Así que no podemos dar nada por hecho o no creer que exista una sola verdad, o que la identidad sea algo compacto e inamovible.

En esta aportación hemos querido analizar brevemente cuáles son los estereotipos de la mujer en el cine de Almodóvar, su relación con las figuras masculinas, llegando a la conclusión de que la mayoría de las veces se trata de identidades separadas o identidades comunes que tienen la finalidad de emprender una política deemancipación de las mujeres y que es la base de la teoría del género (de J. Buttler y Christine Delphy), y también de la teoría queer (de Guy Hocquenghem, Beatriz Preciado, Susana López Penedo entre otr@S much@S).

Almodóvar representa una forma de percibir la realidad, representa estar abierto a la diversidad, a no esperar conductas normativas, a no definir el género de una persona en función de sus genitales, a cuestionar jerarquías, refleja el modo en que se nos presenta el mundo, a visualizar otras realidades y sobre todo otras realidades desde la perspectiva de la práctica feminista como movimiento identitario, que cuestiona el carácter natural de los géneros masculino/femenino, afirmando su construcción social y cultural. Pero..., que cada uno saque su propia lectura.

\section{REFERENCIAS BIBLIOGRÁFICAS}

Albaladejo, M. (1988). Los fantasmas del deseo. A propósito de Pedro Almodóvar. Madrid: Aula 7.

Aronica, D. (2005). Intertextualidades y autorreferencialidad: Almodóvar y el cine español. Miradas y pasión: reflexiones en torno a la obra almodovariana. Cuenca: Universidad de Castilla la Mancha.

Ballesteros, I. (2001). Textos fílmicos y contextos culturales de la España postfranquista. Madrid: Fundamentos.

Barros, R. (2000). La maternidad según Almodóvar. Revista Criterio (2250).

Berriatúa, L. (1997). ¿Qué he hecho yo para merecer esto? En J. Pérez Perucha, Antología crítica del cine español 1906-1995 (págs. 853-855). Madrid: Cátedra/Filmoteca Española. 
Bonatto, V. ( 3 de octubre de 2008). Reescribiendo en género : un análisis de La mala educación de Pedro Almodóvar. I congreso internacional de literatura y cultura españolas contemporáneas . La plata: Facultad de Humanidad y Ciencias de la Educación de la Universidad de La Plata.

Butler, J. (1990). Performative acts and gender constructions: an essay in phenomenology and feminist theory. En S.-E. Case, Performing Feminisms: Feminist Critical Theory and Theater. Baltimore: John Hopkins University Press.

De Lauretis, T. (1996). La tecnología del género. (I. Morant, Trad.) Mora. Revista del Área Interdisciplinar de Estudios de la Mujer (2), 8.,

Donapetry, M. (2004). Cinematernidad. En J. Cruz, \&amp; B. Zecchi, La mujer en la España actual ¿Evolución o involución? (pág. 378). Barcelona: Icaria editorial.

Entrevista a Pedro Almodóvar (1986, abril, 20). Los domingos de ABC. Editorial Prensa Española

Escudero, M. E. (2006). La representación de Madrid o la dicotomía del campo y la ciudad en La flor de mi secreto, de Pedro Almodóvar. Especulo. Revista de estudios literarios .

Fauconnier, D. (2005). Lo grotesco en el cine de Almodóvar. Miradas y pasión: reflexiones en torno a la obra almodovariana (pág. 197). Cuenca: Universidad de Castilla la Mancha.

Fuentes, V. (2005). Buñuel y Almodóvar: un discurso cinematográfico de las pasiones y el deseo. En F.

Zurian, Almodóvar: el cine como pasión (págs. 93-107). Cuenca: Ediciones de la universidad de Castilla La Mancha.

Gabilondo, J. (2005). Melodrama atlántico y migrancia materna. Apuntes sobre Todo sobre mi madre.

Miradas y pasión: reflexiones en torno a la obra almodovariana. Cuenca: Universidad de Castilla la Mancha.

García Abad, M. T. (2005). Cine o literatura en Pedro Almodóvar: Carne trémula \&quot;adaptaciónlibérrima\&quot;. Miradas y pasión: reflexiones en torno a la obra almodovariana. Cuenca: Universidad de Castilla la Mancha.

García, M. L., Llorente, C., \&amp; Cortés, M. S. (2009). \&quot;Tacones lejanos\&quot; madre solo hay una. Prisma social (3).

Gregory, E. (2005). El tratamiento de género en Hable con ella, de Pedro Almodóvar. El caso del amante menguante. Especulo. Revista de estudios literarios (29).

Heredero, C. (1997). Carne trémula. Thiller pasional y carencias emocionales. Dirigido por... (216), 22- 23.

Holguín, A. (2006). Pedro Almodóvar. Madrid: Cátedra. 
Maldonado, G. d. (1989). Pedro Almodóvar, la otra España cañí. Ciudad Real: Biblioteca de autores y temas manchegos.

Markus, S. (2005). Las asesinas inocentes. Miradas y pasión: reflexiones en torno a la obra almodovariana (pág. 420). Cuenca: Universidad de Castilla la Mancha.

Martínez-Vasseur, P. (2003). La España de los 80 en Mujeres al borde de un ataque de nervios. En F. Zurián, \&amp; C. Vázquez Varela, Almodóvar: el cine como pasión (págs. 109-110). Cuenca: Ediciones de la Universidad de Castilla-La Mancha.

Méjean, J. (2007). Pedro Almodóvar. Barcelona: Manon Troppo. Sánchez-Alarcón, M. I. (2008). El color del deseo que todo lo transforma: claves cinematográficas y matrices culturales en el cine de Pedro Almodóvar. Cielo , 11.

Sangro, P., \&amp; Plaza, J. (2010). La representación de las mujeres en el cine y la televisión contemporáneos. Barcelona: Laertes.

Zurián, F. A., \&amp; Vázquez Varela, C. (2005). Almodóvar :el cine como pasión. Cuenca: Universidad de Castilla la Mancha. 